\title{
Combating hysteresis with output targeting
}

\author{
Thomas R. Michl and Kayla M. Oliver* \\ Department of Economics, Colgate University, USA
}

\begin{abstract}
Hysteresis, path dependence, and multiple equilibria are characteristic features of postKeynesian economics. This paper constructs an otherwise conventional three-equation model that includes a hysteresis-generating mechanism and an invariant output target. We use it to explore the implications for monetary policy of an output-targeting policy framework that seeks to reverse the damage caused by hysteresis. We restrict ourselves to negative aggregate demand shocks and positive inflation shocks that in most instances require a disinflationary response from the central bank. One important finding is that as long as inflation expectations are to some degree anchored, the central bank can achieve its output target after an aggregate demand shock by overshooting its inflation target temporarily and running a 'high-pressure labor market.' If expectations are unanchored, an aggregate demand shock will not have long-run hysteresis effects because the central bank is obliged to reflate aggressively, replacing on a cumulative basis all the demand that was lost through the shock. However, with unanchored expectations a pure inflation shock will create hysteresis effects since the central bank will need to disinflate and it does not have the option of running a high-pressure labor market. Anchoring gives the central bank this option, making inflation shocks manageable.
\end{abstract}

Keywords: monetary policy, hysteresis, path dependence, divine coincidence, inflationexpectations anchoring

JEL codes: $E 11, E 12, O 42$

\section{INTRODUCTION}

In the aftermath of the global financial crisis (GFC) of 2008-2009, mounting evidence supports the hypothesis that advanced capitalist economies display hysteresis or path dependence. Hysteresis complicates the task of central banks charged with stabilizing inflation. In its presence, a strong argument can be made that the monetary policy framework should incorporate the fact that the response to an aggregate demand shock can have permanent effects on output and employment. Indeed, the Full Employment and Balanced Growth Act of 1978 (known informally as the Humphrey-Hawkins Act) legally obligates the US Federal Reserve System to pursue 'maximum employment,' which is generally understood to mean the highest employment level consistent with stable inflation. Janet Yellen, Chair of the Board of Governors of the Fed, has placed

* Corresponding author: email: tmichl@colgate.edu. The authors thank the faculty and students in the 2017 Colgate Economics Honors Seminar, Michalis Nikiforos, and two anonymous referees of this journal for helpful comments and suggestions, while taking responsibility for any opinions expressed or errors committed. Thomas Michl is a Professor of Economics at Colgate University and Kayla Oliver graduated from Colgate with majors in Molecular Biology and Economics in 2017. 
research on the problem of hysteresis high on her wish list of policy-significant research topics, observing that 'hysteresis effects - and the possibility they might be reversed - could have important implications for the conduct of monetary and fiscal policy' (Yellen 2016).

This paper proposes a modification to the conventional textbook three-equation model that guides much of the pedagogy and actual practice of monetary policy. It assumes that the central bank cares about the long-run equilibrium levels of output and employment in formulating an optimal policy by minimizing a standard quadratic loss function. In addition to choosing an inflation target, the central bank chooses an output target (which may be different from the temporary equilibrium level of output) so that after a demand or inflation shock it endeavors to reverse the damage done by hysteresis mechanisms.

Because the conventional approach to monetary policy also leads to some kind of reaction function such as the Taylor rule that includes an output target, we will adopt the terminology that in the approach explored in this paper the central bank adopts an invariant output target; for economy of language we will usually refer to this simply as the output target. ${ }^{1}$ The conventional approach accepts the accelerationist hypothesis that (i) the equilibrium level of output (or employment) is supply-determined, (ii) the central bank has to accept the equilibrium level that prevails, and (iii) trying to achieve a higher level of output will result in inflation rising without limit (misleadingly called accelerating inflation).

We build on Michl (2018) which shows that in the presence of hysteresis mechanisms the conventional accelerationist policy framework leads without qualification to permanent output losses after pure inflation shocks; it leads to permanent output losses after aggregate demand shocks unless inflation expectations are completely unanchored. In contrast, this paper asks how the central bank can avoid permanent output losses by adopting an output-targeting policy framework. We seek to introduce a heterodox or unconventional element (hysteresis) into an otherwise conventional three-equation model for the dual purpose of generating a pedagogical resource and contributing to the discussion about the conduct of monetary policy when demand shocks have permanent supply-side effects. ${ }^{2}$

One significant finding in this paper is that the central bank will generally need to overshoot its inflation target if it wants to achieve both its inflation and output targets, which seems intuitive and supports a position taken by some economists. ${ }^{3}$ Yet unless it places no weight at all on the inflation gap the central bank will need to undershoot its

1. Skott (1997) includes a 'pure output target' in a game-theoretic model of the inflation process that is similar to our invariant target, while Lima et al. (2014) also consider an output target that is defined independently of any inflation-neutral equilibrium (if it exists).

2. While there are at least as many differences among heterodox economists as there are among conventional macroeconomists, it seems safe to say that they all reject the idea that capitalist economies gravitate toward some unique natural or supply-determined growth path with full employment of capital and labor; see Dutt (2006). Taylor (2004) or Lavoie (2014) provide good overviews of the heterodox landscape.

3. There are other arguments for overshooting, including the idea that price level targeting is superior to inflation targeting (Hatcher and Minford 2014) and the optimal control approach to policy which optimizes dynamically (Brayton et al. 2014) over the whole adjustment path rather than statically (as we assume in this paper) on a period-by-period basis. Some (Bernanke 2017; Kiley and Roberts 2017) have suggested that overshooting the inflation target helps stabilize output near the zero or effective lower bound on interest rates. 
output target for the same reason, which is not so intuitive and may present a communication challenge. Another finding is that the central bank's ability to achieve both its inflation and output target depends critically on the presence of some degree of anchoring of long-term inflation expectations.

\section{EVIDENCE FOR HYSTERESIS}

The empirical support for hysteresis is compelling. As Lawrence Summers put it in a speech given in 2014 and cited in Ball (2014, p. 1): 'This financial crisis has confirmed the doctrine of hysteresis more strongly than anyone might have supposed.' Some circumstantial evidence for hysteresis after the GFC is provided in Figure 1. The left panel of Figure 1 shows that the employment-population ratio of working-age adults in the US has yet to recover its previous peak before the crisis by a margin of around 2.0 percentage points. If we date the onset of secular stagnation to 2001, as some have argued, this ratio is around 3.3 percentage points below its previous peak. While some of this behavior probably reflects slow demographic shifts in the population, such as the increased weight of older cohorts who tend toward lower participation, empirical research such as Mason (2017) or Yagan (2017) finds that much of the declining employment rate represents the shadow cast by past economic shocks.

Since the model we develop in this paper is static, the employment population ratio is probably the best real-world referent for the output target, which might be thought of as the level of output associated with a target employment rate. In practice, in other words, it would be more meaningful to speak of employment targeting than of output targeting. In the theoretical model we use in this paper, the two would be equivalent.

The right panel of Figure 1 shows the extent to which official estimates of potential GDP have been revised downward in the aftermath of the GFC. It is evidence like this that forms the basis for Ball's (2014) case for hysteresis. Comparing official estimates of potential GDP from the Organisation for Economic Co-operation and Development
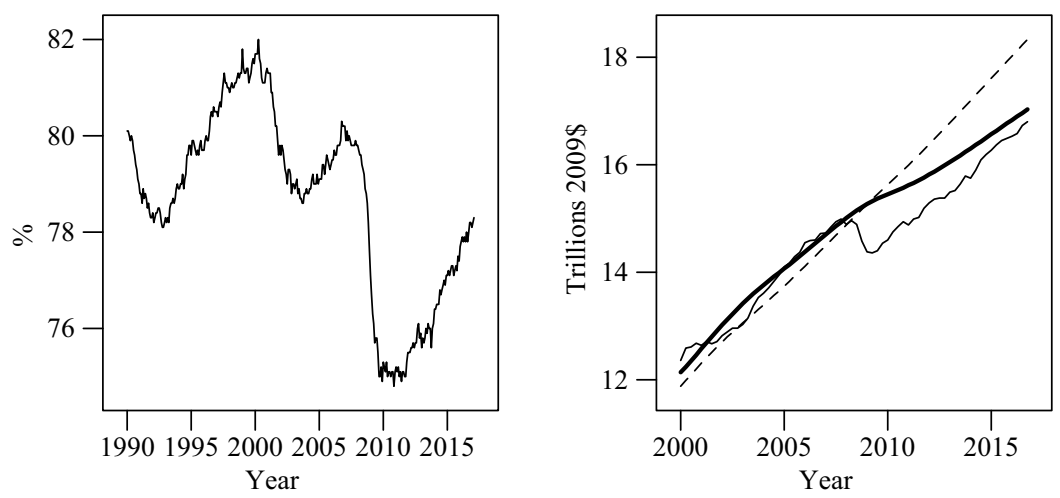

Sources: Left: FRED; right: Congressional Budget Office.

Figure 1 Left: Employment-population rate, US, all persons aged 25-54; right: CBO estimates of potential GDP from 2008 (dashed line) and 2017 (black solid line); actual GDP is the gray solid line 
(OECD) both before and after the GFC, he estimates the average loss of potential output to be 8.4 percent in OECD countries and reaches the astonishing conclusion that due to hysteresis effects the GFC resulted in a global loss of output equivalent to the entire German economy. ${ }^{4}$

In the rest of this paper, we construct an otherwise conventional three-equation model that includes a hysteresis-generating mechanism and an invariant output target. We use it to explore the implications for monetary policy of an output-targeting policy framework. We restrict ourselves to negative aggregate demand shocks and positive inflation shocks which require a disinflationary response from the central bank and hence in most instances imply negative demand shocks.

\section{A THREE-EQUATION MODEL WITH OUTPUT TARGETING}

We will use the notation and terminology from a widely used macroeconomics textbook (Carlin and Soskice 2015) in order to keep the exposition accessible. Variables that are dated will carry a time subscript only when needed for disambiguation. We will suppress the $t$ in representing variables (so $z_{t-1}$ will be written $z_{-1}$ ). Parameters will have identifying numerical subscripts, and it will generally be clear that these are not time signatures.

The foundation for the three-equation model is an augmented Phillips curve, socalled because it includes two elements that did not appear in William Phillip's original equation linking inflation (wage inflation in his case) to the level of economic activity (unemployment rates in his case). First, we have allowed for the possibility that the inflation process is anchored by long-term expectations that the central bank will hit its inflation target. Second, we have included lagged inflation. The augmented Phillips curve is

$$
\pi=\chi \pi^{T}+(1-\chi) \pi_{-1}+\alpha\left(y-y_{e}\right) .
$$

The slope of the Phillips curve, $\alpha$, reflects the sensitivity of wage and price setting to economic slack. Here inflation expectations are anchored by the inflation $\operatorname{target}, \pi^{T}$, chosen by the central bank, with $0 \leq \chi \leq 1$ measuring the extent of anchoring. There is considerable evidence that, since the 1990s, as inflation targeting has become the prevailing form of monetary policy (and perhaps because of this trend), inflation expectations have become increasingly anchored and less responsive to variation in the actual inflation rate (IMF 2013; Blanchard 2016). The equilibrium level of output, $y_{e}$, represents the current level of activity at which inflation stabilizes. In the presence of hysteresis mechanisms (multiple equilibria), of course, this will be changing over time in response to shocks and policy responses.

The presence of lagged inflation in the Phillips curve has traditionally been associated with backward-looking or adaptive expectations, and there is nothing inherently wrong with that interpretation. However, it can also be seen as a reflection of the inertial character of the inflation process. For example, Carlin and Soskice (2015) propose that the last realization of the inflation rate is a natural focal point for bargaining between workers and firms over current pay raises. This does not mean that either party expects that inflation rate to continue, or even that both parties share the same

4. It is worth noting that there is also substantial evidence for hysteresis predating the GFC; see Ball (2009). 
expectation about inflation. The role of the inflation target can also be interpreted through this lens but we will refer to it as a reflection of long-run expectations anchoring, as is traditional. We think this broader interpretation of the augmented Phillips curve makes a certain amount of sense for a workhorse model like the three-equation model but we will use language consistent with the expectations interpretation that is more familiar.

Monetary policy operates through a simple linearized IS equation with a one-period lag between the real interest set by policy, $r$, and the level of aggregate demand. This IS equation is

$$
y=A-a r_{-1},
$$

where the parameter $a$ represents the interest sensitivity of demand and the parameter $A$ represents autonomous spending.

The central bank is assumed to minimize a quadratic loss function period-by-period. ${ }^{5}$ If the central bank followed an accelerationist policy framework, it would accept whatever equilibrium level of output it observed in measuring the loss from any output gap. But with invariant output targeting, the central bank measures the output gap against its output target, which is generally going to be larger than the equilibrium level of output since we are restricting ourselves to negative demand and positive inflation shocks. The loss function is

$$
L=\left(y-y^{T}\right)^{2}+\beta\left(\pi-\pi^{T}\right)^{2},
$$

where $y^{T}$ represents the output target and $\beta$ represents the relative weight ${ }^{6}$ placed on missing the inflation target, $\pi^{T}$.

Choosing an output target is as much an art as it is a science but so too is choosing an inflation target. As in the medical arts, central-banking practices are informed by evidence but ultimately rest on professional judgments. ${ }^{7}$ In this paper, we will simply assume that the central bank targets the existing equilibrium level of output and employment (that is, that the economy initially operates at the output target) and tries to repair the damage done by any negative shocks. We leave aside the practical question of choosing an output target, as well as the related question of how to deal with positive demand shocks. (On a separate note, we also stay clear of the problem of the effective lower bound on interest rates.)

The central bank solves an optimization problem by minimizing the loss function subject to the constraint offered by the Phillips curve. From the first-order condition

5. A referee of this journal has pointed out that the central bank should optimize over the whole adjustment path. This approach using optimal control theory was in fact mooted by Janet Yellen during her chairmanship at the Federal Reserve Board; see Brayton et al. (2014). Since the optimal control approach can underwrite inflation overshooting, which could somewhat obscure our central claim that output targeting requires inflation overshooting, and since the static formulation remains standard in the literature, we have chosen to stick with it.

6. More generally, we could write the loss function as $L=\beta_{y}\left(y-y^{T}\right)^{2}+\beta_{\pi}\left(\pi-\pi^{T}\right)^{2}$ so that $\beta=\beta_{\pi} / \beta_{y}$. This formulation leaves open the possibility that the central bank puts no weight on the output loss, which is an extreme case we briefly examine below.

7. As Paul Krugman $(2014$, p. 1) observes about the two percent inflation target adopted widely in the 1990s, 'Why 2 percent, rather than 1 or 3 ? The target wasn't arrived at via a particularly scientific process, but for a time 2 percent seemed to make both economic and political sense.' 
for this simple minimization problem, we have the monetary rule schedule showing the central bank's desired outcome in any given period: ${ }^{8}$

$$
y=y^{T}-\alpha \beta\left(\pi-\pi^{T}\right) .
$$

In order to model the hysteresis process, we choose to make the current equilibrium level of output a convex combination of past levels of actual and equilibrium output. This adds a fourth equation to the core model (we continue to refer to this expanded model as the 'three-equation model' for identification purposes):

$$
y_{e}=\theta y_{-1}+(1-\theta) y_{e-1},
$$

where $\theta$ measures the strength of the hysteresis-generating mechanism and $0<\theta \leq 1 .{ }^{9}$

Michl (2018) offers a more detailed derivation of this equation of motion based on a particular hysteresis mechanism grounded in Post-Keynesian theories of wage setting with variable real wage aspirations and price setting with variable mark-up norms (Skott 2005; Stockhammer 2008). But the modeling choice made in equation (3) seems to be consistent with the full range of hysteresis mechanisms that have been proposed in the literature. These include insider-outsider effects (Lindbeck and Snower 1986), increases in unemployment duration resulting in skills obsolescence (Layard and Nickell 1986), and losses in capital stock (Soskice and Carlin 1989; Rowthorn 1999). The three-equation model with output targeting in this paper is to that extent catholic in scope.

This formulation treats the hysteresis-generating mechanism as symmetrical or twosided. In keeping with the uncertainty about the "possibility they [hysteresis effects] might be reversed' expressed in the earlier quote from Janet Yellen, we will also consider the implications if the hysteresis mechanisms are one-sided while the central bank operates on the assumption that they are symmetric. ${ }^{10}$

In practice the central bank uses the interest rate to achieve its objective of reaching the monetary rule schedule by obeying a reaction function often called the Taylor Rule. With output targeting, demand shocks will create a gap between the equilibrium level of output and the target level of output through hysteresis effects. We will call the interest rate that stabilizes inflation at the current equilibrium level of output $r_{s}$

8. To be more precise, the monetary rule solves the following minimization problem:

$$
\begin{array}{cc}
\text { minimize } & L=\left(y-y^{T}\right)^{2}+\beta\left(\pi-\pi^{T}\right)^{2} \\
\text { subject to } & \pi=\chi \pi^{T}+(1-\chi) \pi_{-1}+\alpha\left(y-y_{e}\right) .
\end{array}
$$

The first order condition for this problem is

$$
\partial L / \partial y=\left(y-y^{T}\right)+\alpha \beta\left((1-\chi)\left(\pi_{-1}-\pi^{T}\right)+\alpha\left(y-y_{e}\right)\right)=0
$$

which simplifies using the Phillips curve to the monetary rule schedule, equation (2).

9. One possible refinement might treat the hysteresis-generating process as non-linear. For example, small shocks to demand and output may have an attenuated effect on equilibrium while large shocks have an amplified effect. Additionally, it is possible for the severity of the change in equilibrium output to depend on the duration of shocks as well as the severity. Indeed, one view is that true hysteresis requires discontinuities or non-linearities; see Dutt (1997) for an overview of this controversy. We have adopted a tractable hysteresis mechanism to focus attention on the question of how output targeting modifies monetary policy when hysteresis is reversible.

10. Lavoie (2018) provides a useful critical discussion of the treatment of two-sided hysteresis by mainstream economists. 
and the interest rate that stabilizes output at its target level $r^{T}$. Explicit expressions for these rates can be easily obtained from the IS curve.

By using these definitions, the Phillips curve and the monetary rule schedule, we can derive an expression for the Taylor rule: ${ }^{11}$

$$
r=\frac{r^{T}+\alpha^{2} \beta r_{s}}{1+\alpha^{2} \beta}+h\left(\pi=\pi^{T}\right),
$$

where $h=\alpha \beta(1-\chi) /\left(1+\alpha^{2} \beta\right)$. Significantly, this is the same coefficient that we would obtain for a Taylor rule associated with an accelerationist policy framework that accepts $y_{e}$ as the implicit output target. In the absence of hysteresis effects $(\theta=0), r_{s}=r^{T}$ and our Taylor rule would collapse to the standard textbook form for a three-equation model like this.

The Taylor rule most frequently seen in the macroeconomics literature includes the output gap (defined using the current equilibrium level of output) as well as the inflation gap. Carlin and Soskice (2005) explain that this form results when lagged output is used in the Phillips curve to model the output gap: the 'double lag' model. (They also provide some pedagogical and theoretical arguments in favor of the single lag approach.) We have chosen the simpler single lag version because it isolates the key point that output targeting does not require that the central bank respond explicitly to the output gap since it achieves its objectives by managing the inflation process less 'hawkishly' than an accelerationist central bank. We are confident that our main finding, developed below, that this will generally require overshooting the inflation target, would also go through in the double lag model.

The difference between invariant output targeting and an accelerationist policy shows up in the intercept term in the Taylor rule above. For negative demand shocks we can expect $y_{e}<y^{T}$, which implies that $r_{s}>r^{T}$. It follows that an output-targeting central bank will choose a lower interest rate compared to an accelerationist central bank (which would effectively assume that $r^{T}=r_{s}$ ) when confronted with the same inflation gap.

This system of dynamical relations, equations (1)-(3), can be reduced dimensionally and solved for any two of the three main endogenous variables, $\pi, y$, and $y_{e}$. We have chosen to solve for the level of output and the level of equilibrium output since that gives the most transparent mathematical forms. Written in matrix form, we have:

$$
\mathbf{y}=\mathbf{A} \mathbf{y}_{-\mathbf{1}}+\mathbf{b},
$$

where the column vector $\mathbf{y}=\left[y_{e}, y\right]^{\prime}$. The matrix $\mathbf{A}$ and column vector $\mathbf{b}$ are:

$$
\begin{gathered}
\mathbf{A}=\left(\begin{array}{cc}
(1-\theta) & \theta \\
\frac{\alpha^{2} \beta(1-\theta)}{1+\alpha^{2} \beta} & \frac{1+\chi+\alpha^{2} \beta \theta}{1+\alpha^{2} \beta}
\end{array}\right) \\
\mathbf{b}=\left(\begin{array}{c}
0 \\
\frac{\chi y^{T}}{1+\alpha^{2} \beta}
\end{array}\right) .
\end{gathered}
$$

11. The first step is to use the IS curve to express the output gaps as $y-y^{T}=a\left(r^{T}-r_{-1}\right)$ and $y-y_{e}=a\left(r_{s}-r_{-1}\right)$. Substituting these into equations (1) and (2) and then solving this twoequation system leads to the Taylor rule. 
This kind of linear system of first-order difference equations presents no special technical difficulties. The dynamics that we examine in the next two sections depend on the eigenvalues or characteristic roots of the matrix $\mathbf{A}$.

\section{OVERSHOOTING WITH DEMAND SHOCKS}

The most significant feature of the dynamics of this system of difference equations is that with some exceptions it involves overshooting the inflation target and undershooting the output target after a demand shock. The mirror symmetry here is no accident since after a shock (demand or inflation) the central bank immediately takes steps to recover its desired or optimal position which will always be some point on the monetary rule schedule, equation (2). Thus, overshooting the inflation target necessarily implies undershooting the output target. ${ }^{12}$ We can begin by considering a temporary negative aggregate demand shock which takes the system to a point on the prevailing Phillips curve to the southwest of the bliss point, $\left(y^{T}, \pi^{T}\right)$.

We consider a demand shock represented by point $\mathrm{S}$ in Figure 2 . The shock occurs in period $t=-1$, placing the initial conditions in period $t=0$. We will examine three representative initial conditions which correspond to three assumptions about the degree of expectations anchoring. In each case, the central bank will select its optimal response to the Phillips curve trade-off anticipated in the next period. These special cases illustrate how the characteristic dynamic behavior of this model arises from interaction between two distinct stabilizing mechanisms, the first involving managing the inertial inflation process and the second involving the interaction of hysteresis dynamics and the inflation process.

Figure 2 shows the Phillips curves projected for period zero under different assumptions about anchoring, together with the monetary rule schedule and the new equilibrium output level created by the negative shock according to equation (3). The central bank's objective is to manage the inflation and hysteresis processes so that the economy remains on the monetary rule schedule and eventually arrives at the bliss point, $\left(y^{T}, \pi^{T}\right)$. We are interested in the central bank's policy choice in the period of the shock, which determines the output level and inflation rate in the next period (recall that the policy rate affects output with a one-period lag). The central bank is assumed to know the structure of the economy, including the hysteresis process.

In the special case of zero anchoring $(\chi=0)$, the optimal choice is represented by point A. In subsequent periods, the central bank will reflate the economy, bringing inflation back up to its target value. In this case, the central bank's task is effectively to manage the inertial inflation process, or to manage expectations under the adaptive expectations interpretation of the Phillips curve.

This illustrates the first stabilizing mechanism that shapes the behavior of the threeequation model with output targeting. By running the economy 'hot,' above both the equilibrium and the target output levels in order to manage inflation expectations, the central bank is also achieving the objective of managing the hysteresis process,

12. One exception that might be of some interest involves placing no weight at all on the inflation gap (that is, $\beta=0$ ) so that the monetary rule is a vertical line at $y^{T}$. By assumption, there will be no output undershooting in this special case which we discuss further below. 


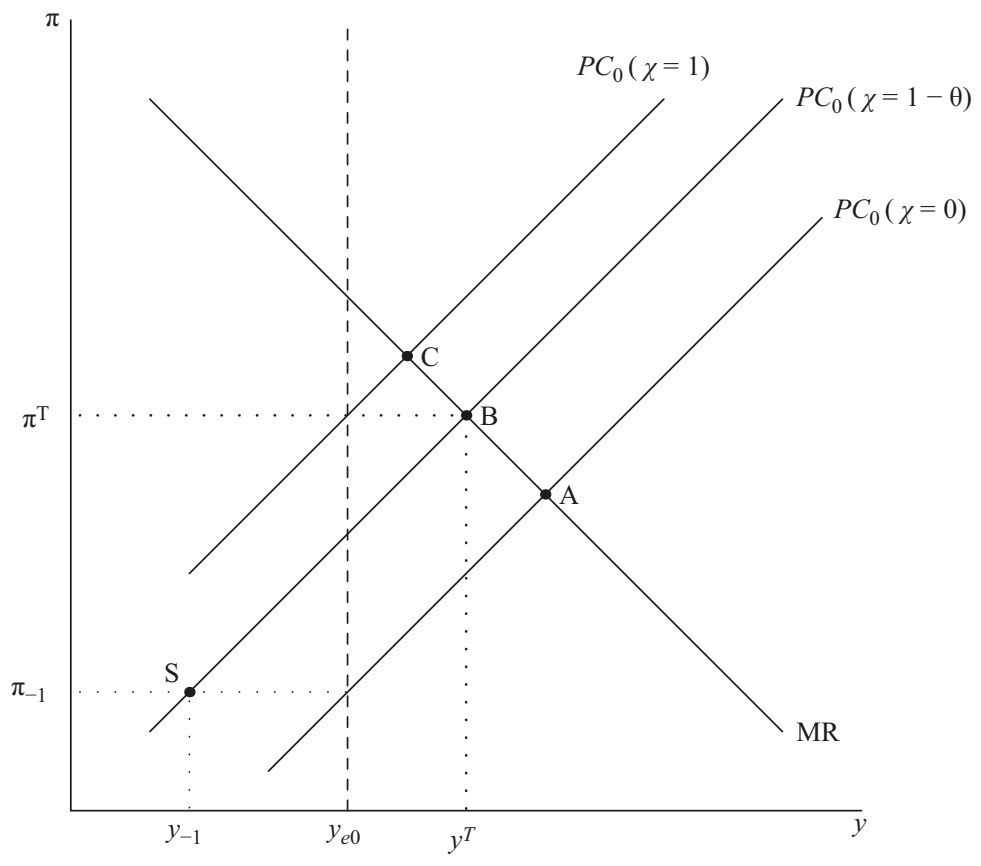

Figure 2 A demand shock (point $S$ ) in period $t=-1$ with three representative initial conditions in period $t=0, A, B$, and $C$; these are associated with alternative degrees of inflation expectations anchoring $(\chi)$ which identify three alternative Phillips curves $(P C)$. For expository purposes the Phillips curve attached to point $B$ contains point $S$ by construction. In each case, the central bank responds to the shock by choosing its best option (points $A, B$, and $C$ ) on the monetary rule schedule (MR).

undoing the damage done by the demand shock. Consequently, in this special case inflation and equilibrium output will converge on their long-run values from below, while output converges on its long-run value from above. There is no overshooting of inflation or undershooting of output.

In this special case, invariant-output targeting is not needed to return the system to its original state; an accelerationist framework would also do the trick. The explanation lies in the mechanics of the augmented Phillips curve which forces the central bank to replace the lost output on a cumulative basis in order to return inflation to its target. Even though this system has a unit root in this case and therefore has no unique long-run equilibrium solution, a demand shock will create no negative hysteresis effects because the central bank is obliged to replace, on a cumulative point-year basis, any demand that has been lost. With these unique conditions, the model illustrates what Blanchard and Galì $(2005$, p. 2) have called the 'divine coincidence,' namely that 'stabilizing inflation also stabilizes the output gap.' In a sense the divine coincidence represents a kind of conservation principle.

To sum up, in the absence of any expectations anchoring, the central bank is obliged to replace all the demand lost through a pure demand shock. As a result, the system will inevitably converge on its inflation and output targets at precisely 
the same time. The task of stabilizing inflation alone is enough to guarantee that demand shocks have no permanent hysteresis effects.

On the other hand, any amount of anchoring relieves the central bank of the need to replace the lost demand on a cumulative basis. With shifts in inflation expectations attenuated by anchoring, the central bank needs to introduce less demand stimulus to manage the inertial inflation process and raise inflation to its target. The inflation rate will inevitably arrive at its target level before the equilibrium level of output has had a chance to recover the target level. The fact that $y_{e}$ has not returned to the target level necessitates that the Phillips curve continues shifting upward, driven by the rise in $y_{e}$ caused by positive hysteresis effects. Inflation must overshoot the target, and output must similarly undershoot the output target.

Point B in Figure 2 illustrates the configuration facing the central bank at this point. Point B represents a special case chosen for expository purposes in which the central bank is able to achieve its inflation and output targets immediately in response to the demand shock, which occurs when the degree of anchoring (by a fluke) satisfies $\chi=1-\theta$. In this special case, the Phillips curve does not shift at all in the period after the shock, which explains why point $\mathrm{S}$ lies on the same Phillips curve as point $\mathrm{B} .{ }^{13}$ Its expository value derives from the fact that under any scenario that starts at a point to the southeast of point B (except point A, of course) the central bank will eventually encounter a point like point $\mathrm{B}$, with $y_{e}<y^{T}$, because of the collapse of the symmetry between the demand shock and the policy response. It will then choose to overshoot its inflation target and correspondingly undershoot its output target. ${ }^{14}$

We can see from point B that the central bank has no choice but to overshoot its inflation target. In the next period, inflation expectations shift to $\pi^{T}$, pushing the Phillips curve leftward. The hysteresis process will increase the equilibrium level of output, attenuating the leftward shift in the Phillips curve. The central bank will then choose a position on its monetary rule schedule that overshoots its inflation target and undershoots its output target. But we know that this pattern can only be temporary because the system lacks a unit root when $\chi$ is non-zero and therefore converges on its target long-run equilibrium, $\left(y^{T}, \pi^{T}\right)$. The movement to the northwest along the monetary rule schedule must eventually reverse itself.

In the special case of full anchoring, $\chi=1$, this reversal is instantaneous, as illustrated by point $\mathrm{C}$ in Figure 2. In this case, the central bank does not have to manage an inertial inflation process. The central bank will respond to the inflation shock by immediately choosing point $\mathrm{C}$, with a dramatic overshooting (undershooting) of its inflation (output) target. Notice that the initial negative hysteresis effect from the demand shock created an inflationary output gap simply by lowering equilibrium output, which explains why inflation initially goes up above the target rate. In subsequent periods the hysteresis mechanism will raise equilibrium output, shifting the Philips curve to the right, relaxing the constraint on the central bank, and permitting it to move inflation and output closer to target.

13. We derived the condition for this outcome $(\chi=1-\theta)$ by using equations (3) and (1) to eliminate $y_{e 0}$ and $\pi_{-1}$ in the Phillips curve shown at point $\mathrm{B}$ in Figure 2, $\pi^{T}=\chi \pi^{T}+(1-\chi) \pi_{-1}+\alpha\left(y^{T}-y_{e 0}\right)$.

14. To be more precise but less heuristic, any qualifying scenario that starts to the southeast of point $B$ will eventually enter a neighborhood of point B from which the central bank will choose to jump over the bliss point and overshoot its inflation target. 
The full time profile for all three scenarios is illustrated in Figure 3, which shows the impulse response functions generated in simulations after a negative demand shock with the three values for the degree of anchoring $\chi{ }^{15}$

The special case of full anchoring illustrates the second important mechanism at work in this model. As we have assumed that hysteresis is two-sided, a positive hysteresis mechanism stabilizes inflation by shrinking the output gap. This mechanism explains why any overshooting of inflation eventually reverses itself.

Indeed, the inflation-stabilizing power of a positive hysteresis mechanism opens up the possibility that the central bank can target output and ignore inflation (that
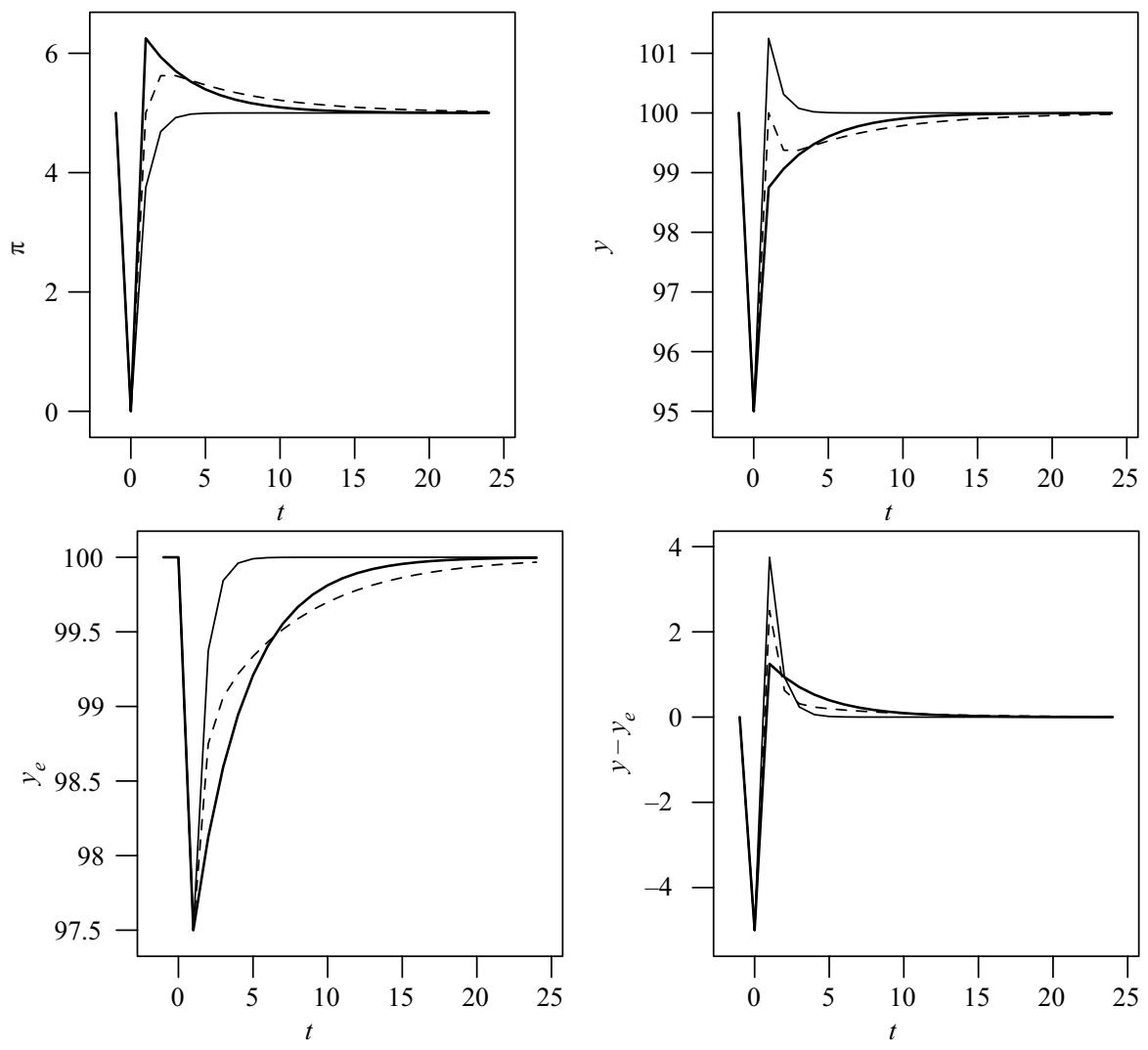

Figure 3 Impulse response functions for a -5 percent demand shock with $\chi=0$ (thin solid line), $\chi=1-\theta$ (dashed line), and $\chi=1$ (bold line). Other parameters are $\theta=0.5, \alpha=\beta=1, \pi^{T}=5$, and $y^{T}=100$. If expectations are anchored to any degree $(\chi>0)$ the central bank will choose to overshoot its inflation target and undershoot its output target.

15. Since the model is set in discrete time, the impulse response functions should technically be regarded as a series of points, not as continuous functions. We have joined them together for visual effect. 
is, set $\beta=0) .{ }^{16}$ In this case, the monetary rule schedule is vertical and the central bank will simply keep output at its target level until equilibrium output has had a chance to recover. If the initial response indicated by the model puts the system below the target inflation rate (which happens when $\chi<1-\theta$ ), the inertial process described above will reflate the system, overcoming the deflationary impulses from the hysteresis mechanism. In this case, we can be sure that eventually the system will arrive at a point similar to B in Figure 2, where the inflation target is achieved before the hysteresis effects of the negative shock have been reversed (that is, where $y_{e}<y^{T}$ ). It is easy to see that inflation overshooting occurs once this point is reached.

If the initial response puts the system above the target with $\beta=0$, the hysteresis mechanism can be counted on to reduce inflation by closing the output gap over time. In this case, the system starts off by overshooting the inflation target.

How does the central bank manage to hit its inflation target in this extreme case? The answer lies in the presence of expectations anchoring in the inflation process. With some credibility surrounding the central bank's ability to achieve its inflation target, expectations about inflation will slowly drift back to the target. ${ }^{17}$ As long as some agents believe the central bank will ultimately defend its inflation target, the central bank does not in fact have to respond to the inflation gap at all. With no anchoring, of course, this option is not available as inflation shocks (but not demand shocks) would never be reversed.

On the other hand, a central bank that operated with an unlimited weight $(\beta \rightarrow \infty)$ on hitting its inflation target, so that its monetary rule is simply $\pi=\pi^{T}$, would find itself locking in some degree of hysteresis. ${ }^{18}$ This is another special case in which a unit root appears. In the extreme case where there is complete anchoring, the entire hysteresis effect of a demand shock would be locked in. At the other extreme, with no anchoring there will be no hysteresis effects owing to the divine coincidence. But any amount of anchoring breaks the symmetry described above and leads to hysteresis effects. These results are illustrated in Figure 4 which shows the impulse response functions for a negative demand shock with different degrees of inflation-gap aversion, $\beta$.

For a more formal demonstration of all the results in this section, readers are invited to consult Appendix 1.

\section{INFLATION SHOCKS}

A pure inflation shock can be modeled as an increase in inflation that does not affect output. The initial condition for the system would then depend on what point on the monetary rule schedule the system achieves in period $t=0$, which as before varies with the degree of expectations anchoring. In any case except $\chi=1$, this point will lie to the northwest of the bliss point because the central bank will engineer an artificial

16. Note that this is not an option when there is no expectations anchoring.

17. Formally, with $y=y^{T}$ we can see from the Phillips curve that the first difference of inflation will be negative, indicating declining inflation: $\pi_{+1}-\pi=-\chi\left(\pi-\pi^{T}\right)$.

18. Recall from footnote 3 that this amounts to setting the absolute weight on the output gap to zero $\left(\beta_{y}=0\right)$. 

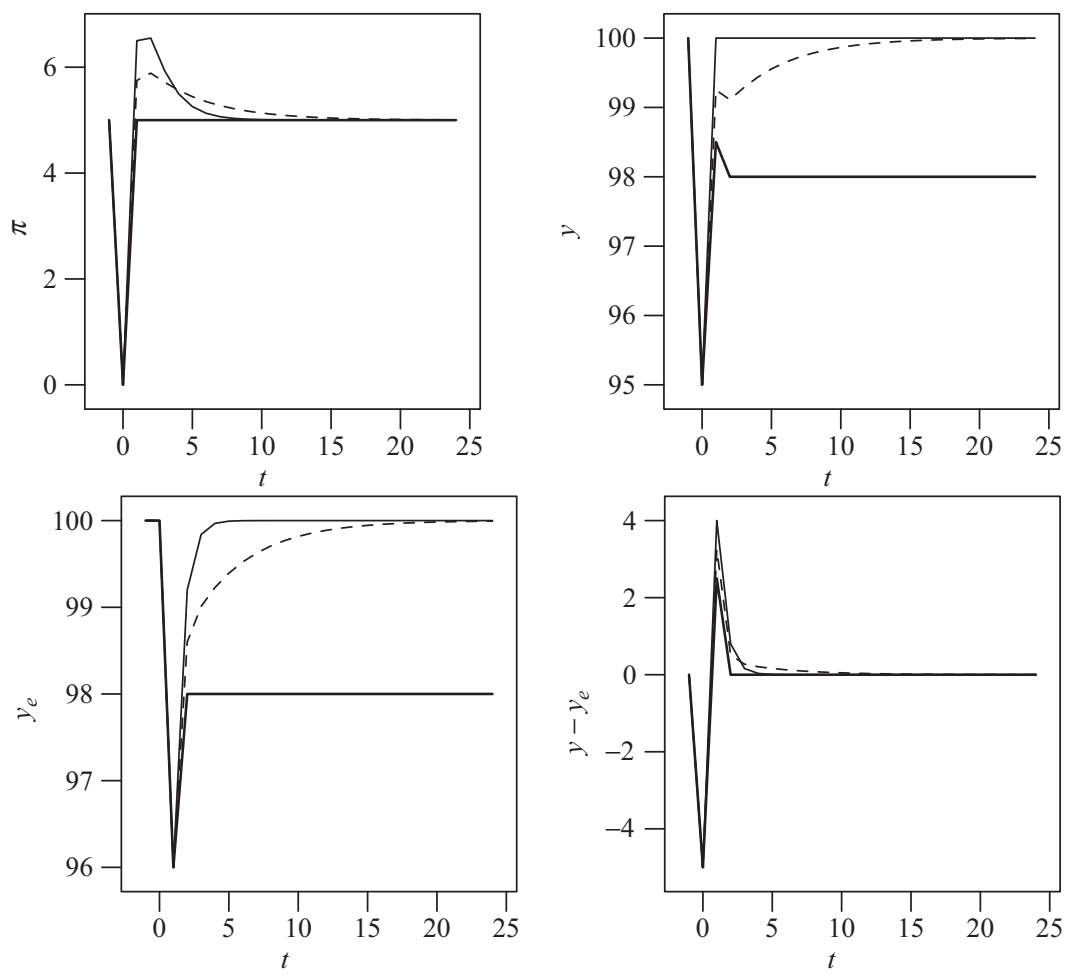

Figure 4 Impulse response functions for $a-5$ percent demand shock with $\beta=0$ (thin solid line), $\beta=1$ (dashed line), and $\beta \rightarrow \infty$ (bold line). Other parameters are $\chi=0.5$, $\theta=0.8, \quad \alpha=1, \pi^{T}=5$, and $y^{T}=100$. As long as expectations are anchored to some degree, the central bank has the option of ignoring its inflation target, but not its output target.

recession to disinflate the system. ${ }^{19}$ This need to use economic slack to manage the inflation process accounts for the generation of hysteresis effects after an inflation shock. The central bank subsequently allows output to increase until the system returns to the bliss point except in the two special cases with unit roots.

With a positive inflation shock we can see clearly the economic principles underlying the two cases with unit roots in this model $(\chi=0$ and $\beta \rightarrow \infty)$. First, when there is no anchoring, any pure positive inflation shock will necessarily create permanent negative hysteresis effects on output because it requires the central bank to create a cumulative negative output gap that disinflates away the shock ('squeezing inflation out of the system'). Without expectations anchoring there is absolutely no room to run the system hot. The actual level of output can never exceed the equilibrium level of output, and as a result the system will always settle down below the target level of output, with a corresponding permanent inflation gap. With a unit root the

19. If $\chi=1$ the central bank will take the system back to the bliss point immediately with no hysteresis repercussions at all. 
equilibrium will lie somewhere on the monetary rule schedule, depending on initial conditions. $^{20}$

Inflation expectations anchoring reduces the cumulative negative output gap that will be required and permits the central bank to harness the hysteresis mechanism by running a 'high pressure labor market' with output above its equilibrium level during the transitional dynamics in order to reverse the damage done by hysteresis. The impulse response functions shown in Figure 5 illustrate these points.

An interesting corollary of this result is that with output targeting, as long as it enjoys some credibility (anchoring), a central bank that wants to reduce the longrun inflation rate - as many central banks did in the 1980s - can achieve this objective without inflicting any permanent damage. (A reduction in inflation target is isomorphic to a temporary inflation shock.) Under an accelerationist operating
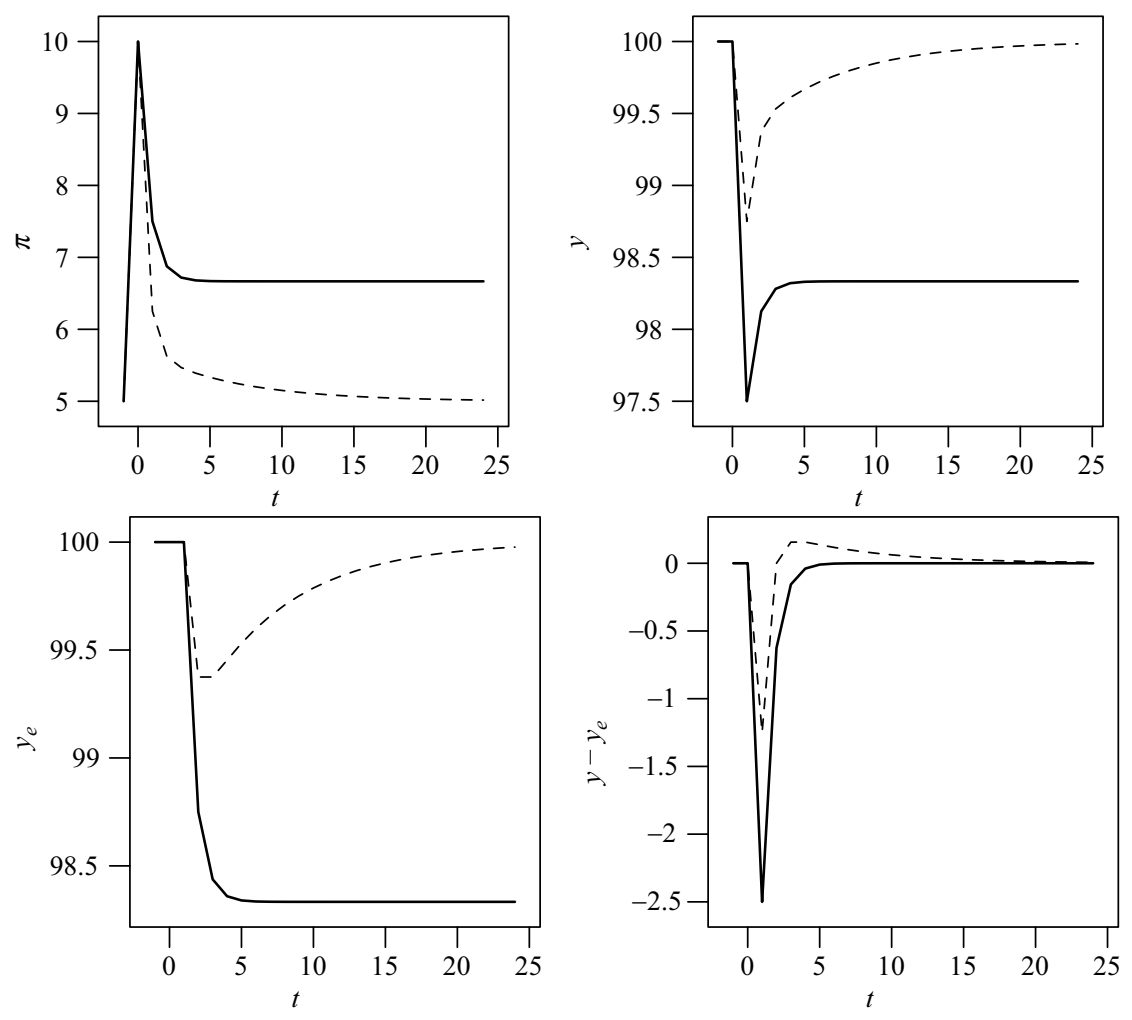

Figure 5 Impulse response functions for $a+5$ percentage point inflation shock with $\chi=0$ (bold solid line) and $\chi=0.5$ (dashed line). Other parameters are $\theta=0.5$, $\alpha=1, \pi^{T}=5$, and $y^{T}=100$. When expectations are unanchored an inflation shock causes hysteresis effects as a consequence of disinflation.

20. This means that when there is no anchoring and a shock occurs, the Phillips curve in place forms the boundary between negative hysteresis effects and positive hysteresis effects (which we have excluded from discussion) just as it does in an accelerationist policy framework (Michl 2018). A pure demand shock pushes the system along this boundary, resulting in no longterm hysteresis effect, as we saw above. 
framework, however, a disinflationary policy will leave behind permanent scars through hysteresis effects.

The other route to a unit root runs through the central bank assigning zero weight to the output gap. In this case, the model collapses to an accelerationist regime in which the central bank simply accepts whatever equilibrium output level it confronts. Again, the central bank locks in any negative inflation shock because it forgoes the opportunity to run the system hot. The transitional dynamics are trivially simple in this case. After a demand or inflation shock, the new long-run position will be achieved in just two periods when $\chi<1$ and one period when $\chi=1$. $^{21}$

A more formal demonstration of these findings can be found in Appendix 1.

\section{ONE-SIDED HYSTERESIS}

Perhaps the leading reason central bankers like Janet Yellen are reluctant to incorporate hysteresis into their routine operating procedures is the lack of evidence that hysteresis is truly two-sided. The weight of evidence supporting negative hysteresis effects does not necessarily imply the converse (Ball 2014), namely that positive effects are equally strong or even that they exist at all. In this light it makes good sense to consider the outcome of an invariant output target in the event that the policymakers were wrong and tried to reverse the negative hysteresis effects of a demand shock in the presence of one-way (negative only) hysteresis. In particular, would this lead to the nightmare of endlessly increasing inflation from which the soubriquet 'accelerationist' first arose?

It turns out the answer in this model is no, and the reason is close at hand. By adopting an inflation-targeting policy and implementing it through a Taylor rule, the central bank is committing itself to the more general Taylor principle which states that the policy response to any increase in inflation should be to raise nominal rates by more than the increase in inflation. In other words, monetary policy following any increase in inflation should raise the real interest rate. Under this operating procedure, the central bank will stabilize inflation, even if it fails to achieve its inflation target or its output target.

A simple modification of equation (3) allows for one-sided hysteresis through the incorporation of a $\min$ function:

$$
y_{e}=\min \left[y_{e-1}, \theta y_{-1}+(1-\theta) y_{e-1}\right] .
$$

From the monetary rule schedule and Phillips curve, it is easy to show that the system will stabilize around a point on its monetary rule schedule to the northwest after a demand shock that lowers equilibrium output to $y_{e}<y^{T}$. Using asterisks to indicate the steady-state values, this point has the coordinates:

$$
\begin{gathered}
y^{*}\left(\frac{\chi}{\chi+\beta \alpha^{2}}\right) y^{T}+\left(\frac{\beta \alpha^{2}}{\chi+\beta \alpha^{2}}\right) y_{e} \\
\pi^{*}=\pi^{T}+\frac{\alpha}{\chi}\left(y^{*}-y_{e}\right) .
\end{gathered}
$$

21. Formally this behavior reflects the fact that the characteristic roots are $\lambda_{1}=1$ and $\lambda_{2}=0$ in this case. 
Only if the central bank gives the inflation target zero weight will it be able to hit the output target, but the price paid will be a gap between the inflation rate and its target inflation rate that depends on the degree of anchoring. In the case of low levels of anchoring, this would not be practical as it would result in an accelerationist dystopia of very high inflation, and zero anchoring would make it completely unfeasible.

This is clearly not a sustainable state of affairs since both the central bank and those private agents whose expectations are anchored would find that inflation realizations conflict with their expectations on a persistent basis. The central bank would have to reconsider its operating framework in light of this information. If it didn't, private agents would certainly abandon expectations anchoring and the central bank would lose credibility.

Pursuing output targeting in a world with one-sided hysteresis would at worst involve a learning process. The central bank would observe inflation running persistently above target and would need to change its policy framework. Something similar is also true in the standard three-equation model, without hysteresis, when the central bank chooses the wrong value for the inflation-neutral rate of interest and misses its inflation target. Given the magnitude of the social cost of hysteresis, output targeting seems like a worthwhile policy to try despite uncertainty about two-sided hysteresis.

\section{CONCLUSION}

Central banks in a world characterized by symmetric (two-sided) hysteresis effects can stabilize output by choosing an invariant output target in addition to the traditional inflation target. This paper shows how invariant-output targeting might work in a standard three-equation model with path dependence (a bedrock Keynesian principle). ${ }^{22}$ The main lesson is that as long as the inflation process is anchored to the central bank's inflation target to some extent, there should be no inherent problem in undoing the damage caused by a major demand or inflation shock.

The complete absence of anchoring does present a problem because inflation shocks require a disinflationary stance that will inflict permanent damage on output and employment. With no anchoring demand shocks do not have permanent effects because of the 'divine coincidence' created in this special case: the cumulative reflation will always be just sufficient to repair any damage inflicted by hysteresis effects. This symmetry breaks down when there is any expectations anchoring, and this is the key reason why invariant-output targeting is needed in the general three-equation model. It is also the key to understanding why inflation overshooting and output undershooting are necessary as long as there is some degree of anchoring.

This finding presents inflation expectations anchoring in an ironic light. When in the presence of two-sided hysteresis the central bank pursues inflation targeting under the accelerationist hypothesis (the conventional operating procedure), negative demand shocks will generally create negative effects on long-term output and employment as long as there is any anchoring at all. The reason, again, is the breakdown of the symmetry noted above because anchoring absolves the central bank of

22. This raises the question of how policy would be altered if even more Keynesian elements were introduced. For example, Lima et al. (2014) use an alternative non-accelerationist treatment of the inflation process and also endogenize the process by which inflation expectations become anchored through satisficing evolutionary dynamics. Interestingly they reach a similar conclusion about the ability of the central bank to achieve both an output and inflation target. 
the need to reflate aggressively. Only in the absence of anchoring do the central bankers benefit from the divine coincidence with respect to demand shocks. Anchoring, often considered a virtue, emerges as a vice under an accelerationist policy framework. But when the central bank drops the accelerationist dogma and adopts an invariant output target, anchoring re-emerges as a virtue because it creates the space to run a high-pressure labor market and repair the damage from large demand shocks as well as inflation shocks. Economists (in particular heterodox economists) who have traditionally treated central-bank credibility with some skepticism might be advised to embrace the goal of credibility since it provides central banks with the power to combat hysteresis.

Fear of one-way hysteresis effects has been expressed by economists and central bankers but the problems raised by this possibility appear manageable. A central bank operating on the premise of two-sided hysteresis effects that do not exist would find itself permanently overshooting its inflation target. It would have to reconsider its policy framework ex post, or else it might experience a loss of confidence and deterioration in expectations anchoring. But it would not lose control of the inflation process because it would be observing the Taylor principle in setting policy rates. Experimentation with output targeting in an uncertain world appears unobjectionable.

We have set several important questions aside, including the obvious practical and theoretical issue of how to establish an output target. Even if that obstacle is cleared, there remains the challenge of communicating the need to undershoot the output target and overshoot the inflation target during the adjustment process after a demand shock. In addition, complications might arise from the constraint offered by the effective lower bound on interest rates.

An important lesson for central bankers, professional economists, and indeed for the informed citizenry is that an optimal response to a demand shock in the presence of twosided hysteresis effects and expectations anchoring requires at least some overshooting of the inflation target in order to repair the damage caused by the hysteresis mechanism. Policy normalizations after the global financial crisis could represent premature tightening from this perspective. We hope the model presented here will help disseminate this message before the next major economic crisis rocks the world, if not sooner.

\section{APPENDIX 1 TECHNICAL APPENDIX}

Some readers may find it useful to see a more formal demonstration of the properties described in Sections 4 and 5.

The characteristic roots or eigenvalues of the matrix A can be expressed compactly as

$$
\lambda_{1,2}=\frac{2+\alpha^{2} \beta-\chi-\theta \pm \sqrt{D}}{2\left(1+\alpha^{2} \beta\right)},
$$

where the discriminant is $D=\left(\alpha^{2} \beta\right)^{2}+(\theta-\chi)^{2}+2 \alpha^{2} \beta(\theta+\chi-2 \theta \chi)$. It is easy to show that the discriminant is positive $(D>0)$ so that the roots are strictly real. ${ }^{23}$ This rules out oscillations and keeps the dynamics fairly simple.

23. Since all the terms are positive except the very last one, the sufficient condition for $D>0$ is $\theta+\chi-2 \theta \chi>0$ and this condition is clearly satisfied for permissible parameter values. 
The stability of the system depends on the condition that the roots lie within the unit circle. To identify the dominant root we will adopt the convention that $\lambda_{1}>\lambda_{2}$. For given values of the other parameters, we can express the roots as functions of $\chi$ and characterize their behavior as follows:

$$
\begin{gathered}
\lambda_{1}=f(x) \quad f^{\prime}(\chi)<0 \quad f(0)=1 \quad f(1)=\frac{1-\theta+\alpha^{2} \beta}{1+\alpha^{2} \beta} \\
\lambda_{2}=g(\chi) \quad g^{\prime}(\chi)<0 \quad g(0)=\frac{1-\theta}{1+\alpha^{2} \beta} \quad g(1)=0 \\
\lambda_{2}<1-\theta<\lambda_{1} .
\end{gathered}
$$

We see immediately that the roots lie weakly within the unit circle. Only in the cases of $\chi=0$, no anchoring of inflation expectations, and $\beta \rightarrow \infty$ will the dominant root be equal to one (unity). ${ }^{24} \mathrm{We}$ can be confident the system will be stable and absent a unit root it will converge on a unique equilibrium at the bliss point $\left(y^{T}, \pi^{T}\right)$.

We can demonstrate the prevalence of over/undershooting by finding the general solution of the homogeneous system attached to equation (4). Following Gandolfo (1997), this can be written as

$$
\begin{aligned}
& y_{e}=A_{1} \lambda_{1}^{t}+A_{2} \lambda_{2}^{t} \\
& y=A_{1}\left(\frac{\lambda_{1}-(1-\theta)}{\theta}\right) \lambda_{1}^{t}+A_{2}\left(\frac{\lambda_{2}-(1-\theta}{\theta}\right) \lambda_{2}^{t},
\end{aligned}
$$

where $A_{1}$ and $A_{2}$ are constant terms that depend upon the initial conditions.

Defining the first-differences using $\Delta y=y_{+1}-y$, we have:

$$
\begin{gathered}
\Delta y_{e}=A_{1}\left(\lambda_{1}-1\right) \lambda_{1}^{t}+A_{2}\left(\lambda_{2}-1\right) \lambda_{2}^{t} \\
\Delta y=A_{1}\left(\lambda_{1}-1\right)\left(\frac{\lambda_{1}-(1-\theta)}{\theta}\right) \lambda_{1}^{t}+A_{2}\left(\lambda_{2}-1\right)\left(\frac{\lambda_{2}-(1-\theta)}{\theta}\right) \lambda_{2}^{t} .
\end{gathered}
$$

These equations allow us to identify convergence from below (above) in which case the first difference will be positive (negative). We can characterize the dynamics using these equations by considering a negative unit demand shock, $y_{-1}=y^{T}-1$ chosen to occur in period $t=-1$ so that we can place the initial condition in period $t=0$. Using equations (1), (2), and (3) the initial conditions can be written:

$$
y_{e 0}=y^{T}-\theta \quad y_{0}=y^{T}+\gamma(1-\chi-\theta),
$$

where $\gamma=\alpha^{2} \beta /\left(1+\alpha^{2} \beta\right)$.

From the general solution ${ }^{25}$ specialized to $t=0$ we can definitize the constant terms:

24. Note that as $\beta \rightarrow \infty, f(1) \rightarrow 1$, and $g(0) \rightarrow 0$.

25. The general solution is the general solution to the homogenous system plus the particular solution which will be $\left(y^{T}, y^{T}\right)$ aside from the cases with a unit root. The particular solution is derived by solving equation (4) for the stationary state assuming that $\lambda_{1}<1: \mathbf{y}=\mathbf{y}_{-\mathbf{1}}=\overline{\mathbf{y}}=(\mathbf{I}-\mathbf{A})^{-1} \mathrm{~b}$. In the presence of a unit root, $(\mathbf{I}-\mathbf{A})$ is singular and its inverse is not defined. 


$$
\begin{gathered}
A_{1}=-\theta-A_{2} \quad A_{2}=\left(\frac{\theta}{\lambda_{2}-\lambda_{1}}\right)\left(\gamma(1-\chi-\theta)+\lambda_{1}-(1-\theta)\right) \\
A_{1}, A_{2} \leq 0
\end{gathered}
$$

The dynamics of equilibrium output and output depend on the sign configuration of terms on the right-hand sides of equations (A1) and (A2) which is reported in Table A1 for values of $\chi$ corresponding to the three special cases examined in detail in Section 4 with labels that correspond to those in Figure 2. These three special cases exhibit the three qualitative time profiles that the system is capable of generating.

From the fact that $A_{1}$ and $A_{2}$ are non-positive and from restrictions on $\lambda_{1}$ and $\lambda_{2}$ listed above, we can confirm from equation (A1) that equilibrium output must converge on its long-run value from below in all cases.

The dynamics of output depend on the relative sizes of the two terms on the righthand side of equation (A2). As long as $\lambda_{1}<1$, the first term will always dominate since the second term will reach zero before the first term (recall that $\lambda_{1}$ is the dominant root), again making use of the reported restrictions on $\lambda_{1}$ and $\lambda_{2}$.

It follows that $\Delta y$ will become positive at some point along any trajectory without a unit root, which signifies convergence from below or undershooting. Since the dynamics take place along the monetary rule schedule, equation (2), it is clear that inflation will mirror output and converge on its long-run equilibrium value from above, or overshooting. ${ }^{26}$ This can happen in one of two ways.

First, when $\chi=1$ as in case C, the second term in equation (A2) zeros out and as a result the dynamics are monotonic; $\Delta y$ remains positive throughout the adjustment process. (This behavior will also occur for values of $\chi$ that are close to unity as well, because the second term is eclipsed by the first term.)

Second, for intermediate values of $\chi$ such as case $\mathrm{B}$, the second term in equation (A2) will initially dominate so that output will be declining for some interval of time before it reverses course to converge on its long-run equilibrium from below. (In case B, this interval will be quite short but for smaller values of $\chi$ it will be longer.) Again, the reversal reflects the fact that the first term is driven by the dominant root.

On the other hand, when $\chi=0$ we can see that output converges monotonically on its long-run equilibrium from above, since the first term in equation (A2) has vanished in case A and all the action comes through the second term, which is negative, so that $\Delta y<0$.

To sum up, as long as $\lambda_{1}<1$ (no unit root), the first term in the difference equation for output which is associated with the larger root will eventually dominate the

\section{Table A1 Initial conditions after a unit demand shock}

\begin{tabular}{lccccc}
\hline Case & $\chi$ & $\lambda_{1}$ & $\lambda_{2}$ & $A_{1}$ & $A_{2}$ \\
\hline A & 0 & 1 & + & 0 & $-\theta$ \\
B & $1-\theta$ & + & + & - & - \\
C & 1 & + & 0 & $-\theta$ & 0 \\
\hline
\end{tabular}

26. This argument does not apply to the special case in which the central bank assigns a zero weight to the inflation gap and holds the level of output at its target throughout the adjustment process. An informal proof that applies to this case appears in the previous section. 
dynamic path. This means that even if the first difference starts off negative, it will eventually turn positive as the second term shrinks toward zero faster than the first term. In economic terms, this establishes the undershooting of output and (since the dynamics occur along the monetary rule schedule) the overshooting of inflation.

It remains to be shown that the central bank will reverse the damage from hysteresis in the case with no anchoring $(\chi=0)$. This amounts to showing that starting from some time period, $t=s$, when the shock occurs the differences in equilibrium output will sum to zero over a long time horizon, or $\sum \Delta y_{e}=0$. From equation (3) we can see that

$$
\sum_{t=s}^{\infty} \Delta y_{e}=\theta \sum_{t=s}^{\infty}\left(y-y_{e}\right)
$$

From the Phillips curve (with $\chi=0$ ) we can derive the well-known sacrifice ratio which shows the cumulative sacrifice of output needed to disinflate when the inflation gap is positive or, in our case, the cumulative output gap needed to reflate the system when the inflation gap is negative:

$$
\frac{\sum_{t=s}^{\infty}\left(y_{+1}-y_{e+1}\right)}{\pi^{T}-\pi_{s}}=\frac{1}{\alpha} .
$$

We can combine these two relationships by expanding the summation of output gaps and substituting from the sacrifice ratio to obtain:

$$
\sum_{t=s}^{\infty}\left(y-y_{e}\right)=\left(y_{s}-y_{e_{s}}\right)+\sum_{t=s}^{\infty}\left(y_{+1}-y_{e+1}\right)=\left(y_{s}-y^{T}\right)+\frac{1}{\alpha}\left(\pi^{T}-\pi_{s}\right),
$$

where $y_{s}-y^{T}$ represents the demand shock. Using the Phillips curve, we find that the inflation gap $\left(\pi_{s}-\pi^{T}\right)$ created by the demand shock will be $\alpha\left(y_{s}-y^{T}\right)$ which completes the proof since upon substitution it is clear that $\sum \Delta y_{e}=0$. The cumulative (positive) output gap needed to reflate the system turns out to be exactly the amount needed to reverse the hysteresis effect of the original demand shock. ${ }^{27}$

Remarkably, the foregoing proof does not depend on the particularities of this paper's model and would apply to any monetary policy that stabilizes the inflation rate (this being the essence of the divine coincidence). To arrive at the same conclusion in the present model, begin with equation (A1) and substitute the values of $\lambda_{i}$ and $A_{i}$ specialized for $\chi=0$. Recalling that $\sum_{t=0}^{\infty} \lambda_{2}^{t}=1 /\left(1-\lambda_{2}\right)$, we find that $\sum_{t=0}^{\infty} \Delta y_{e}=\theta$, which is exactly what it takes to offset the initial unit shock that reduced $y_{e}$ by $\theta$.

We can use the same framework to demonstrate that both equilibrium output and output will converge on their long-run equilibria from below after an inflation shock. With a unit inflation shock in period $t=-1, \pi_{-1}=\pi^{T}+1$, we can determine that the initial conditions are

$$
y_{e 0}=y^{T} \quad y_{0}=y^{T}-\Omega
$$

27. An instructive special case is when $\theta=1$. Because $\chi=0$, the central bank will be able to return to the bliss point immediately in period $s+1$. The shock will lower equilibrium output to $y s$ but the reflation in period $s+1$ will restore it to $y^{T}$. 
where $\Omega=\alpha \beta(1-\chi) /\left(1+\alpha^{2} \beta\right)$. From these conditions we can determine the signs of the arbitrary constants:

$$
A_{1}=-A_{2} \quad A_{2}=\frac{\Omega \theta}{\left(\lambda_{1}-\lambda_{2}\right)} \geq 0
$$

Consulting equation (A2) and the restrictions on $\lambda_{1}$ and $\lambda_{2}$, we can see that output will converge on its long-run equilibrium from below, $\Delta y>0$. Consulting equation (A1) we can see that in period $t=0$ equilibrium output will decline (owing to the economic slack created by the central bank) but will converge on its long-run equilibrium from below in all subsequent periods, or $\Delta y_{e}>0$ for $t>0 .{ }^{28}$

To see that the absence of anchoring will lead to hysteresis effects after an inflation shock, we can use equation (A1). Substituting the $\lambda_{i}$ and $A_{i}$ values specialized to $\chi=0$ we find that with the dominant unit root the first term on the right-hand side zeros out. It follows that $\sum_{t=0}^{\infty} \Delta y_{e}=-A_{2}$, illustrating the presence of hysteresis in the absence of expectations anchoring. But without a unit root, the first term on the right-hand side does not zero out and we can see that $\sum_{t=0}^{\infty} \Delta y_{e}=-A_{1}-A_{2}=0$, indicating that any hysteresis effects are reversed.

\section{REFERENCES}

Ball, Laurence M. (2009), 'Hysteresis in unemployment: old and new evidence,' National Bureau of Economic Research, Cambridge, MA, Working Paper No 14818.

Ball, Laurence M. (2014), 'Long term damage from the great recession in OECD countries,' National Bureau of Economic Research, Cambridge, MA, Working Paper No 20185.

Bernanke, Ben S. (2017), 'Monetary policy in a new era,' Peterson Institute, Washington, DC, 'Conference on Rethinking Macroeconomic Policy.'

Blanchard, Olivier (2016), 'The Phillips curve: back to the '60s?' American Economic Review, 106(5), 31-34.

Blanchard, Olivier and Jordi Galì (2005), 'Real wage rigidities and the New Keynesian model,' National Bureau of Economic Research, Cambridge, MA, Working Paper No 11806.

Brayton, Flint, Thomas Laubach, and David Reifschneider (2014), 'Optimal control monetary policy in the FRB/US model,' Board of Governors of the Federal Reserve System, Washington, DC, FEDS Notes.

Carlin, Wendy and David Soskice (2005), 'The 3-equation New Keynesian model: a graphical exposition,' Contributions in Macroeconomics, 5(1), 1534-6005.

Carlin, Wendy and David Soskice (2015), Macroeconomics: Institutions, Instability and the Financial System, Oxford: Oxford University Press.

Dutt, Amitava K. (1997), 'Equilibrium, path dependence and hysteresis in post-Keynesian models,' in Philip Arestis and Malcolm Sawyer (eds), Essays in Honour of G.C. Harcourt: Markets, Unemployment and Economic Policy, vol. 2, London: Routledge, pp. 238-253.

Dutt, Amitava K. (2006), 'Aggregate demand, aggregate supply and economic growth,' International Review of Applied Economics, 20(3), 319-336.

Gandolfo, Giancarlo (1997), Economic Dynamics: Study Edition, Berlin: Springer-Verlag.

Hatcher, Michael and Patrick Minford (2014), 'Stabilization policy, rational expectations and price-level versus inflation targeting: a survey,' Centre for Economic and Policy Research, London, CEPR Discussion Paper No 9820.

28. In period $t=0$ the difference equation for equilibrium output simplifies to $A_{1}\left(\lambda_{1}-\lambda_{2}\right)<0$. In period $t=1$, it simplifies to $A_{1}\left(\left(\lambda_{1}-1\right) \lambda_{1}-\left(\lambda_{2}-1\right) \lambda_{2}\right)>0$. 
IMF (International Monetary Fund) (2013), World Economic Outlook: Hopes, Realities, Risks, Washington, DC: IMF.

Kiley, Michael T. and John M. Roberts (2017), 'Monetary policy in a low interest rate world,' Brookings Papers on Economic Activity, Washington, DC, BPEA Conference Drafts.

Krugman, Paul (2014), 'Inflation targeting reconsidered,' European Central Bank, Frankfurt, Sintra Conference Paper.

Lavoie, Marc (2014), Post-Keynesian Economics: New Foundations, Cheltenham, UK and Northampton, MA: Edward Elgar Publishing.

Lavoie, Marc (2018), 'Rethinking macroeconomic theory before the next crisis,' Review of Keynesian Economics, 6(1), 1-21.

Layard, Richard and Steven Nickell (1986), 'Unemployment in Britain,' Economica, 53(210), S121-S169.

Lima, Gilberto Tadeu, Mark Setterfield, and Jaylson Jair da Silveira (2014), 'Inflation targeting and macroeconomic stability with heterogeneous inflation expectations,' Journal of Post Keynesian Economics, 37(2), 255-279.

Lindbeck, Assar and Dennis J. Snower (1986), 'Wage setting, unemployment, and insideroutsider relations,' American Economic Review, 76(2), 235-239.

Mason, J.W. (2017), What Recovery? The Case for Continued Expansionary Policy at the Fed, New York: Roosevelt Institute.

Michl, Thomas R. (2018), 'Hysteresis in a three-equation model,' Eastern Economic Journal, 44(2), 305-322.

Rowthorn, Robert (1999), 'Unemployment, wage bargaining and capital labour substitution,' Cambridge Journal of Economics, 23(4), 413-425.

Skott, Peter (1997), 'Stagflationary consequences of prudent monetary policy in a unionized economy,' Oxford Economic Papers, 49(4), 609-622.

Skott, Peter (2005), 'Fairness as a source of hysteresis in employment and wages,' Journal of Economic Behavior and Organization, 57(2), 305-331.

Soskice, David and Wendy Carlin (1989), 'Medium run Keynesianism: hysteresis and capital scrapping,' in P. Davidson and J. Kregel (ed.), Macroeconomic Problems and Policies of Income Distribution, Aldershot, UK and Brookfield, VT: Edward Elgar Publishing, pp. 241-255.

Stockhammer, Engelbert (2008), 'Is the NAIRU theory a monetarist, New Keynesian, post Keynesian or a Marxist theory?' Metroeconomica, 59(3), 479-510.

Taylor, Lance (2004), Reconstructing Macroeconomics: Structuralist Proposals and Critiques of the Mainstream, Cambridge, MA: Harvard University Press.

Yagan, Danny (2017), 'Employment hysteresis from the Great Recession,' National Bureau of Economic Research, Cambridge, MA, Working Paper No 23844.

Yellen, Janet (2016), Macroeconomic Research After the Crisis, Board of Governors of the Federal Reserve System, Washington, DC, Speeches. 